\title{
RADAR OBSERVATION OF HEAVY RAIN
}

\author{
By H. WHALLEY and G. J. SCOLES
}

$\mathrm{W}$ HILE certain amount of data on radar obsey ations of tropical rain has been published, the accolnpanying photographs of a radar P.P.I. screep/showing a belt of heavy rain passing over the Mo chester district may be of interest. The wavelength used was $3 \mathrm{~cm}$. and the pulse length 1 micro. second, the photographs being taken on the afternoon of Friday, November 19, 1948, approximate times only being given.

Fig. 1 is a tracing of the P.P.I. picture with the coast-line and certain known points plotted by range and bearing for identification purposes. The radius of the display is about $\mathbf{4 0}$ miles.

Fig. 2 is a photograph, taken at 2.50 p.m., showing a belt of rain more than 30 miles long forming in the west.

Fig. 3 was taken at 3.30 p.m. Note how the rain is moving to the east, giving very strong echoes, the belt being continuous for more than 50 miles. Although not very obvious in the photograph, the centre of this belt is curved backwards, presumably being delayed by the high ground in the Wigan area.

Fig. 4 was taken at $4.20 \mathrm{p} . \mathrm{m}$. The rain belt has passed over Manchester and is much shorter. Note

\author{
Electrical Co., Ltd., Manchester
} the secondary belt of rain following the main one, and the apparent attenuation of the normally strong echo from the hill (Mow Cop) just south of Congleton, possibly due to the two rain belts across this path.

Fig. 5 was taken at 4.35 . The belt has lengthened slightly and the centre is again delayed, possibly due to the high land in the Peak District. A further photograph was taken at 4.45 p.m., which showed that the rain had passed the Peak and appeared to be weaker; this may be due to the masking effect of the hills as the rain passes below the horizon.

The general speckled background in most of the photographs is the effect of receiver noise in the radar system.

The echoes received are from very heavy rain. The observed belt arrived in Manchester a little before 4 p.m. and was pre. ceded by about five miles of light rain. At this period, Ringway Airport reported that $4 \mathrm{~mm}$. of rain fell in 35 minutes. Light rain persisted for more than an hour after the heavy rain passed over.

Fig. 2

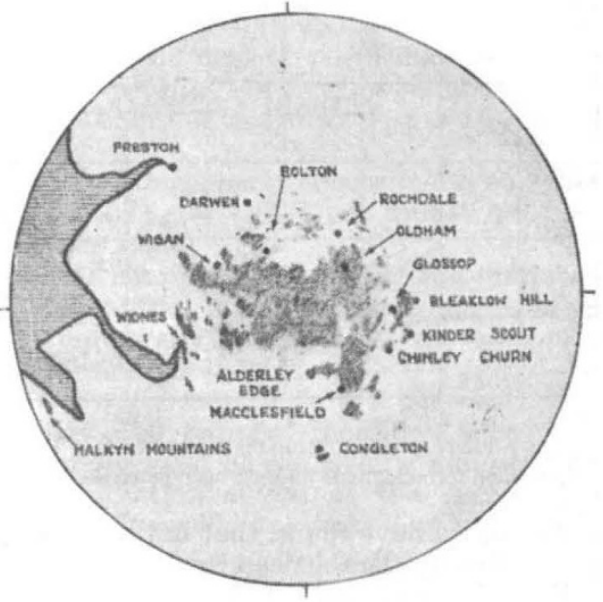

Fig. 1

Fig. 3

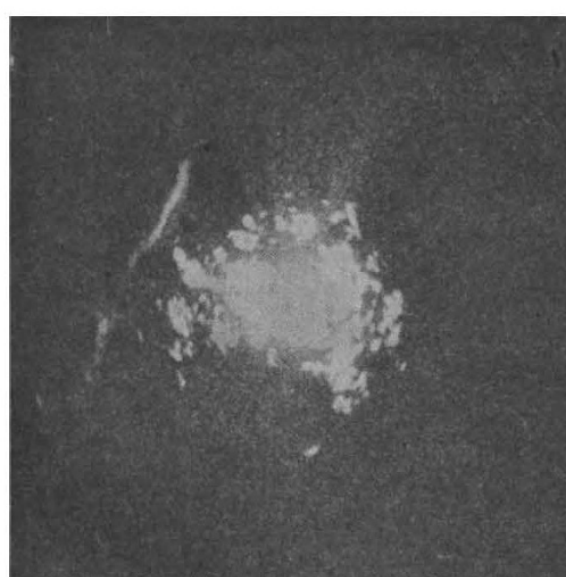

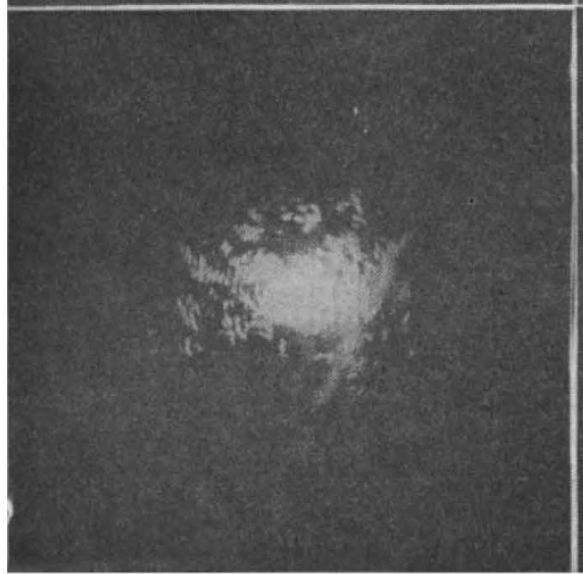

Fig. 4

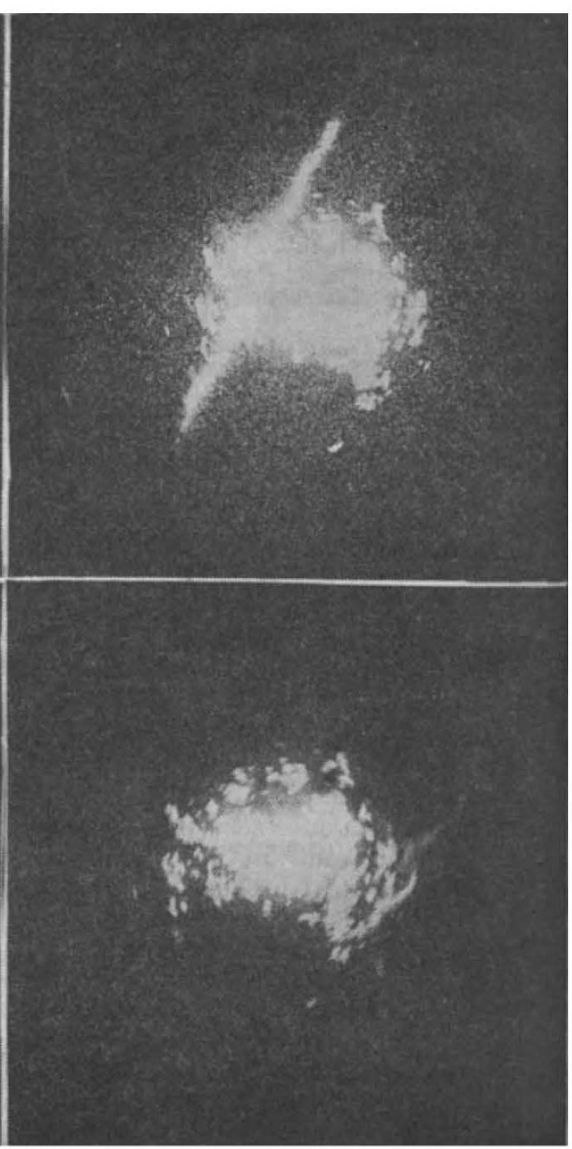

Fig. 5 